\title{
Análise da estrutura organizacional do esporte de rendimento no Brasil: um estudo preliminar $^{1}$
}

CDD. 20.ed. 796.06

\author{
Tatiana de Barros MEIRA* \\ Flávia da Cunha BASTOS* \\ Maria Tereza Silveira BÖHME* \\ *Escola de Educa- \\ ção Física e Esporte, \\ Universidade de São \\ Paulo.
}

\begin{abstract}
Resumo
Em diversos paises, a estrutura organizacional voltada ao desenvolvimento das modalidades esportivas é definida por programas de esporte desenvolvidos nacionalmente. Este estudo teve por objetivo analisar a organização, as estruturas e as políticas para o esporte de rendimento no Brasil. Foram analisadas as ações de órgãos governamentais e/ou entidades nacionais do esporte de alto nível. Foram analisados os 14 Fatores Críticos para o Sucesso (FCS) referentes aos quatro indicadores que compõem o Pilar 2 do modelo SPLISS (Sports Policies Leading to Sport Sucess) (DE BossCHER et al., 2009). Verificou- se que: o pais possui ações isoladas oriundas do COB e do Ministério do Esporte; não existe priorização na aplicação dos recursos financeiros nas modalidades com chances reais de medalhas; existem ações do COB em relação à formação de gestores e técnicos, e a participação da representação de atletas nas entidades nacionais de esporte ainda é bastante restrita e recente.
\end{abstract}

UnIteRMos: Organização esportiva; Políticas esportivas; Esporte de rendimento.

\section{Introdução}

O esporte de alto nível ou de alto rendimento é definido por De Rose, Deschamps e KorsaKas (1999) como aquele no qual o atleta busca alcançar os melhores níveis de desempenho, obtendo assim bons resultados coletiva e/ou individualmente.

As condiçóes ambientais adequadas para o desenvolvimento do esporte de alto rendimento englobam os aspectos referentes ao treinamento esportivo (anos de treinamento, qualidade do treinamento, qualidade do professor/técnico), as condiçôes psico-sócio-econômicas (apoio dos pais, técnicos e colegas, condiçôes financeiras para treinar, apoio médico), assim como o sistema organizacional do esporte na sociedade (nacional e regional) e especificamente da modalidade esportiva considerada (VAN Rossum, 2004).

No Brasil, a estrutura organizacional de uma modalidade esportiva compreende vários níveis de implantação, operacionalização e controle; nos níveis municipal e estadual, por meio dos clubes ou entidades esportivas, controladas por ligas, associações, e federações; nos níveis nacional e internacional, por meio de centros de treinamento e seleçóes nacionais, controlados por confederaçóes, comitê olímpico e federações internacionais (MEIRA \& BASTOS, 2011).

Trabalhos de pesquisa buscam compreender o funcionamento de programas esportivos em diferentes países e, principalmente, naqueles com destaque no contexto internacional (Digel, 2002a,b; GreEN \& Oakley, 2001; Houlihan \& Green, 2008; De Bosscher, Bingham, Shibli, Van Bottenburg \& De Knop, 2008; De Bosscher, De Knop, Van BotTenbrug; Shibli \& Bingham, 2009; De Bosscher, Shibli, Van Bottenbrug, De Knop \& Truyens 2010; Thumm, 2006; Ziemmainz \& Gulbin, 2002).

Nessas pesquisas são analisadas as estruturas esportivas dos países, para valorizar/buscar o entendimento dos vários aspectos que envolvem os seus sistemas esportivos. Os resultados desses estudos apontam que é possível identificar particularidades de acordo com cada país, como também, açôes semelhantes entre eles, indicando a existência de pontos comuns relevantes no desenvolvimento do esporte de alto nível que devem ser destacados e valorizados. 
De Bosscher et al. (2008) afirmam que a sistematização da estrutura organizacional de diferentes países reflete-se em bons resultados esportivos internacionais. Dois exemplos são o Reino Unido e o Canadá. O Reino Unido sistematizou a estrutura esportiva em 1997, após o fracasso nos Jogos Olímpicos de Atlanta em 1996, conseguindo passar da 36 colocação para $10^{\mathrm{a}}$ colocação nos Jogos de Sidney e Atenas, e, alcançando o 40 lugar em Pequim-2008. O Canadá buscou se sistematizar para receber os Jogos Olímpicos de Inverno em Vancouver no ano de 2010, por meio de um plano de treinamento a longo prazo implementado nacionalmente, que levou à conquista da primeira colocação em tais jogos (COMITÊ OlímPICO INTERNACIONAL - COI, 2010; De BossChER et al., 2008).

Os países que alcançam sucesso internacional no esporte de alto nível possuem planos de ações nacionais, sejam esses gerenciados pelo governo, por entidades esportivas, ligas nacionais ou institutos nacionais de esporte, que são elaborados de maneira central, e aplicados em todo o território nacional (De Bosscher et al., 2008; Green, 2004; Green \& OAKley, 2001; Houlihan \& Green, 2008).

Green e OAKley (2001) desenvolveram um estudo comparativo entre países considerados como potências esportivas com a intenção de encontrar pontos em comum na estrutura organizacional que explicassem o seu sucesso esportivo internacional. De acordo com os autores, existe uma tendência nos países com sucesso esportivo no contexto internacional, no sentido de adotarem alguns elementos da organização esportiva utilizados pelos países do antigo Bloco Oriental, apesar das diferenças sociais, culturais, históricas e políticas.

Outra linha de estudo foi desenvolvida por DigEL (2002a,b), comparando estruturas esportivas de países com resultados esportivos internacionais expressivos, com o objetivo de encontrar pontos convergentes e divergentes voltados para o esporte de alto nível, a partir de um modelo de análise desenvolvido pelo mesmo. De acordo com o mesmo, especificamente quanto à estrutura esportiva, o entendimento se dá por meio das interaçôes do sistema esportivo com os seguintes aspectos: política, economia, sistemas de educação, função da ciência com relação ao sucesso no esporte, papel das forças armadas, setor privado como parceiro e patrocinador do esporte, mídia como promotora dos interesses no esporte, e audiência como base para o desempenho esportivo em nível mundial.

Mais recentemente, DE Bosscher et al. (2008) propuseram outra abordagem para a análise do sistema esportivo, considerando-se três níveis de análise: macro, meso e micro. O macro nível compreende as condiçôes gerais (sociais, econômicas, históricas, culturais, entre outras); o meso nível engloba as políticas da sociedade e do respectivo governo voltadas para o esporte; já o micro nível refere-se aos aspectos específicos do treinamento físico e desempenho individual de atletas (FIGURA 1).

Nessa abordagem, a análise no meso nível em cada país possibilita a comparação de estruturas esportivas de diferentes naçôes no sentido de compreender os fatores determinantes do desenvolvimento do esporte de alto nível.

Como resultado da aplicação das diferentes abordagens apresentadas, verifica-se que a maioria das pesquisas da área concentra-se na descrição, identificação e comparação das características dos sistemas esportivos de cada país (Digel, 2002a,b; Green \& Oakley, 2001; Houlihan \& Green, 2008; Thumm, 2006; Ziemmainz \& Gulbin, 2002).

No sentido de promover a sistematização de critérios para análise dos sistemas esportivos que resultam em sucesso no esporte de rendimento, DE Bosscher et al. (2008, 2009, 2010) procuraram validar um modelo dos fatores que levam ao sucesso do esporte de alto nível empiricamente. A partir dos resultados obtidos foi proposto um modelo teórico para a análise da estrutura esportiva que leva ao sucesso internacional denominado SPLISS - Sports Policies Leading to International Sport Success fundamentado em nove pilares (FIGURA 2).

O Pilar 1 é considerado como a Entrada do Modelo e os outros oito pilares fazem parte do Processo. Como Saída do Modelo, é considerado o sucesso esportivo internacional, composto por resultados nos Jogos Olímpicos de Verão, Jogos Olímpicos de Inverno e Campeonatos Mundiais. 


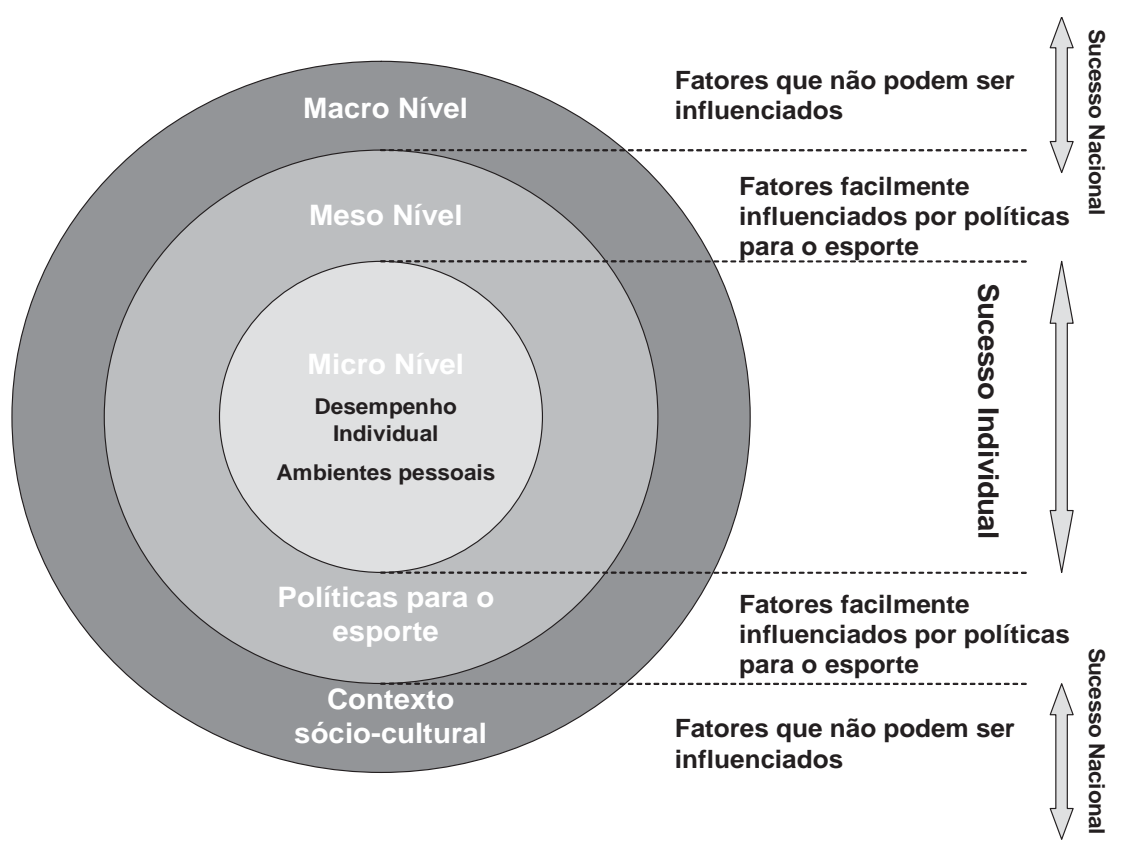

FIGURA 1 - Níveis defatores queinfluenciam o sucesso esportivo internacional (traduzido de De BosschER etal., 2008).

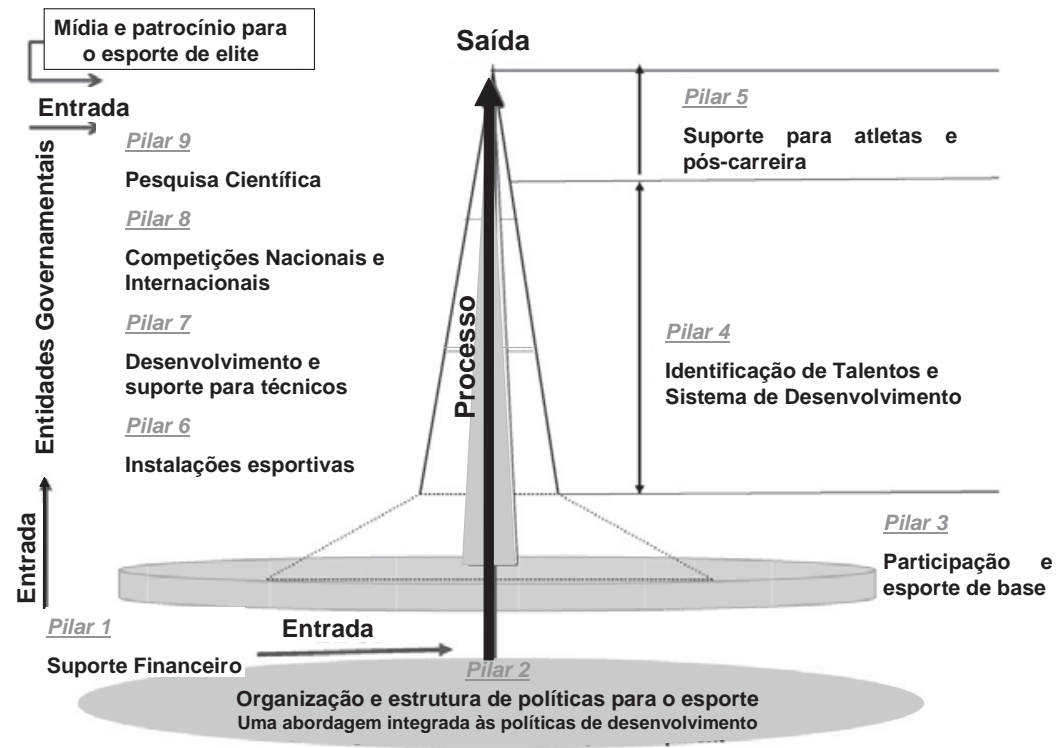

FIGURA 2 - Modelo do SPLISS. Modelo teórico dos nove pilares da estrutura esportiva queinfluenciam o sucesso internacional (traduzido de De Bosscher et al., 2009).

O objetivo dos autores foi elaborar um modelo que permitisse a criação de um "Índice de Desenvolvimento Esportivo" de cada nação, com fundamento na comparação dos níveis de desenvolvimento de cada fator-chave considerado influente no sucesso esportivo internacional. A intenção é que este modelo possa servir de "benchmark" para outros países na área de formulação de políticas para o esporte de alto nível. Nesse sentido, foram estabelecidos os "Fatores Críticos de Sucesso" (FCS) para os "Indicadores" de cada "Pilar", os quais devem ser analisados por meio da aplicação do modelo SPLISS.

De acordo com o exposto, fica clara a importância da estruturação e organização esportiva do país para a obtenção do sucesso esportivo no contexto internacional. Para GREEN e OAKLEY (2001) os dois primeiros fatores-chave correspondem à estruturação do esporte nacionalmente, com o entendimento claro do papel de cada entidade esportiva e a centralização de ações. Na análise de Digel (2002b), é destacado 
que a interação entre fatores da sociedade de forma geral e aspectos específicos do esporte é de grande importância, pois determina a forma pela qual cada país sistematiza o esporte nacionalmente. No modelo SPLISS, proposto por De BossCher et al. (2008, 2009), o Pilar 2, "Organização e Estrutura de Políticas para o Esporte" fundamenta os outros sete pilares considerados para o sucesso esportivo internacional, demonstrando a importância dos seus indicadores com os respectivos fatores críticos para o desenvolvimento do esporte de alto nível de uma nação.

No Brasil, não foram encontrados trabalhos de pesquisa sobre a estrutura organizacional para o esporte de alto nível fundamentados em modelos propostos pela literatura internacional da área. $\mathrm{Na}$ visão de Matsudo (1999), o Brasil possui programas esportivos

\section{Materiais e métodos}

O presente estudo caracteriza-se, quanto aos fins, como de caráter exploratório e descritivo e, quanto aos meios, como pesquisa documental e bibliográfica (VERGARA, 2006).

O projeto de pesquisa ao qual o trabalho apresentado faz parte "Desenvolvimento de atletas de elite: qualidade da detecção, seleção e promoção de talentos esportivos na realidade brasileira e comparação internacional das políticas para o esporte de alto nível" foi aprovado pelo Comitê de Ética na Pesquisa da Escola de Educação Física e Esporte da Universidade de São Paulo, sob o número de protocolo 2010/12.

As informações foram obtidas por meio de levantamento documental e bibliográfico, a partir da identificação de material disponível em bibliotecas, sites de busca (Pubmed, Medline e Scopus) e revistas especializadas. Os descritores definidos para a busca em sites de busca foram: administração esportiva, sucesso esportivo, organização esportiva e programas de esporte, e para refinar a busca de acordo com os objetivos do estudo, todos os descritores foram relacionados ao descritor "esporte de alto rendimento" nos idiomas português e inglês. $\mathrm{O}$ material bibliográfico final considerado restringiu-se a oito artigos originais e dois livros. Também foram levantadas fontes documentais institucionais e legais em sites de órgãos governamentais (Ministério do Esporte) e de entidades esportivas (Comitê Olímpico Brasileiro e Confederações Esportivas). O período de realização de revisão bibliográfica e da busca na Internet ocorreu de agosto de 2009 a julho de 2010. A análise dos dados foi referente a esse mesmo período. assistemáticos, de forma que o Estado, os clubes e a família se responsabilizam pelo desenvolvimento dos atletas. Neste sentido, um estudo sobre a estrutura organizacional esportiva brasileira é relevante para a Educação Física e Esporte no país, pois o conhecimento produzido através da pesquisa sobre o estado da arte do tema poderá contribuir para o desenvolvimento da política e administração para a área.

Este trabalho teve por objetivo descrever a organização, as estruturas e as políticas para o esporte de rendimento no Brasil, por meio da análise da estrutura organizacional e das ações realizadas para o desenvolvimento de esporte de alto nível brasileiro, com base nos fatores críticos dos indicadores do Pilar 2, "Organização e Estrutura de Políticas para o Esporte" do modelo SPLISS, proposto por De BossCHER et al. $(2008,2009)$.

A análise do material obtido foi realizada levando-se em consideração os quatro indicadores e seus respectivos Fatores Críticos para o Sucesso (FCS total de 14) referentes ao Pilar 2, denominado "Estrutura e organização de políticas para o esporte - uma abordagem integrada da política de desenvolvimento", conforme propostos por De Bosscher et al. (2009), respectivamente:

Indicador 1 - Existe uma forte coordenação entre todas as instituições de esporte de elite, com clara definição e sem sobreposição das diferentes tarefas (FSC 1, 2, 3, 4).

Indicador 2 - Existe simplicidade de administração (FCS 5).

Indicador 3 - Os recursos são focados em um número relativamente pequeno de esportes que possuem chances reais de sucesso internacional (FCS 6).

Indicador 4 - Comunicação eficaz: existe uma linha ininterrupta entre os diferentes níveis das instituições esportivas (FCS 7, 8, 9, 10, 11, 12, 13 e 14)

Cabe ressaltar que o estudo conduzido por $\mathrm{DE}$ BOSSCHER et al. (2009) trata-se de um estudo piloto e, assim, os FCSs, assim como os indicadores podem vir a ser modificados futuramente. Optou-se por utilizar esse referencial teórico por tratar-se de uma boa proposição sistematizada e bem fundamentada em trabalhos anteriores relevantes da área. Conforme proposto no título, o presente trabalho trata-se de um estudo preliminar sobre a Estrutura organizacional do esporte de rendimento brasileiro. Este estudo teve como delimitação, o fato de também ter utilizado fontes secundárias de pesquisa junto aos sites das instituições consideradas. 


\section{Resultados}

Os resultados são apresentados considerando-se os indicadores do Pilar 2 do modelo SPLISS, e seus respectivos FCS, conforme propostos por DE BOsSCHER et al. (2009).

\section{Indicador 1:}

"Existe uma forte coordenação entre todas as instituições de esporte de elite, com clara definição e sem sobreposição das diferentes tarefas" (FCS 1, 2, 3, 4)

Em relação ao FCS 1: "Existe uma única organização a nível nacional com responsabilidades específicas em relação ao esporte de alto nível (com tarefa centralizada), excluindo o esporte para todos" - verificou-se que no Brasil, na atualidade, não existe uma única organização a nível nacional com responsabilidades específicas em relação ao esporte de alto rendimento. No nível nacional duas organizações são responsáveis especificamente pelo desenvolvimento do esporte de alto nível: o Comitê Olímpico Brasileiro (COB) e o Ministério do Esporte (ME), por meio da Secretaria Nacional de Esporte de Alto Rendimento. Ambos, juntamente com o Conselho Nacional de Esporte, formam o Sistema Nacional de Esporte que elaboram as políticas para o Esporte de alto rendimento.

A Secretaria Nacional de Esporte de Alto Rendimento tem por objetivo desenvolver o esporte de alto rendimento nacionalmente, por meio da implementação, supervisão e gerenciamento de programas e projetos governamentais. É composta por dois Departamentos, de Esporte de Base e de Alto Rendimento, e o de Excelência Esportiva e Promoção de Eventos (Brasil, 2010b).

Em relação ao FCS 2: "Coordenação da entrada de apoios (direção horizontal): as despesas para o esporte de elite a nível nacional são centralizadas, documentadas e coordenadas, não existe espaço para sobreposição de tarefas" - no Brasil, existe interação horizontal entre o Ministério do Esporte e o COB. $\mathrm{O} \mathrm{COB}$ possui o objetivo de desenvolver os esportes olímpicos no país, para isso recebe repasse de $85 \%$ de $2 \%$ da arrecadação bruta de todas as loterias federais do país, estipulado pela Lei no 10.264 , sancionada em julho de 2001 (Lei Agnelo-Piva), (Brasil, 2001).

Ainda com relação à entrada de recursos financeiros, verificou-se que com objetivo de estimular a captação de recursos da iniciativa privada para o Esporte, foi criada a Lei no 11.438 (Lei de Incentivo Fiscal para o Desporto), que possibilita a concessão de incentivos e benefícios fiscais para empresas e pessoas físicas que fomentarem as atividades de caráter desportivo, para qualquer forma de manifestação do esporte, seja educacional, de lazer ou de alto rendimento.

Segundo esta Lei, de 2007 a 2015 poderão ser destinados até $1 \%$ do imposto de renda devido, em cada período de apuração, trimestral ou anual, pela pessoa jurídica tributada com base no lucro real, os valores despendidos a título de patrocínio ou doação. Quanto à pessoa física, a destinação permitida para este fim é de até $6 \%$ do imposto devido na Declaração de Ajuste Anual. Para tanto, os projetos desportivos e para-desportivos devem ser encaminhados ao Ministério do Esporte para aprovação, para posterior captação de patrocínio (BRAsIL, 2006).

Outras formas de recursos são provenientes de empresas estatais; a Petrobrás, os Correios, a Caixa Econômica Federal, o Banco do Brasil, a Eletrobrás, a Embratel e a Vale do Rio Doce foram e ainda são, em grande parte, responsáveis pelos investimentos feitos em modalidades como basquete, vôlei, natação, ginástica, handebol, vela, entre outros (DIAS \& BASTOS, 2010).

Quanto às interações verticais especificadas pelo FCS 3: "Coordenação da entrada de suporte financeiro (direção vertical): as despesas para o esporte de elite nos níveis regionais e distritais, e se existem despesas de maior importância, são nacionalmente documentadas e coordenadas", verifica-se que na estrutura esportiva brasileira as interaçôes ocorrem separadamente para o Ministério do Esporte e para o COB.

O Ministério do Esporte, por meio da Secretaria Nacional de Esporte de Alto Rendimento, tem como um de seus objetivos:

Prestar cooperação técnica e assistência financeira

supletiva a outros órgãos da Administração Pú-

blica federal, aos Estados, ao Distrito Federal, aos

Municípios e às entidades não governamentais

sem fins lucrativos, em empreendimentos ligados

ao esporte de alto rendimento (BRASIL, 2010b).

Os recursos financeiros gerenciados pelo Ministério do Esporte são os repasses de verba para os Estados da federação que desenvolvem políticas de esporte de maneira autônoma, conforme preconiza a Lei 9.615 (BRASIL, 1998). Dados referentes ao ano de 2009 registrados no Portal da Transparência apontam que esses recursos foram destinados para projetos nos Estados de São Paulo, Rio de Janeiro, Pernambuco, Piauí, Amazonas e o Distrito Federal nas seguintes áreas do Esporte de Alto Rendimento: Funcionamento de Núcleos de Categorias de Base; Capacitação de 
Recursos Humanos; Implantação e Modernização de Centros Científicos e Tecnológicos; Promoção e Participação em Competiçôes Internacionais para Pessoas Portadoras de Deficiência (Brasil, 2010a).

Já o COB possui interação vertical com as Confederaçôes Brasileiras a ele vinculadas. São 30 Confederações de modalidades esportivas que integram o programa dos Jogos Olímpicos de Inverno e de Verão, 21 Confederações Vinculadas e três Confederaçôes Reconhecidas.

A interação entre o $\mathrm{COB}$ e as confederaçôes esportivas olímpicas ocorre por meio de parte do repasse do valor referente aos $85 \%$ da verba proveniente da Lei Agnelo-Piva recebidos do Ministério do Esporte (Brasil, 2010b).

As Confederações Brasileiras, por sua vez, têm interação vertical com as Federações Esportivas de cada Estado Brasileiro. No entanto, nem todas as Confederações têm a mesma dimensão. A Confederação Brasileira de Atletismo e a Confederação Brasileira de Desportos Aquáticos, entre outras, possuem 27 Federações filiadas. Já outras Confederações, como as de Tiro com Arco, Triathlon, Badminton, entre outras, têm vinculação com um número reduzido de Federações (COB, 2010; CONFEDERAÇÃo BRASILEIRA DE ATLETISMO, 2010; ConfEDERAÇÃo Brasileira de BADMINTON, 2010; Confederação Brasileira de Desportos Aquáticos, 2010; Confederaçấo Brasileira de Tiro com Arco, 2010; ConfederaÇÃo Brasileira de Triatlhon, 2010).

Finalmente, as Federaçôes possuem interação vertical com clubes e entidades de prática esportiva a elas vinculadas nos seus Estados de origem. Um exemplo é a Federação Paulista de Volleyball que possui 64 entidades esportivas vinculadas, representadas por clubes privados, associações esportivas e equipes de prefeituras (FEDERAÇÃo Paulista DE VolleyBall, 2010).

A FIGURA 3 representa as interações verticais na estrutura organizacional esportiva brasileira voltada para o desenvolvimento do esporte de alto nível.

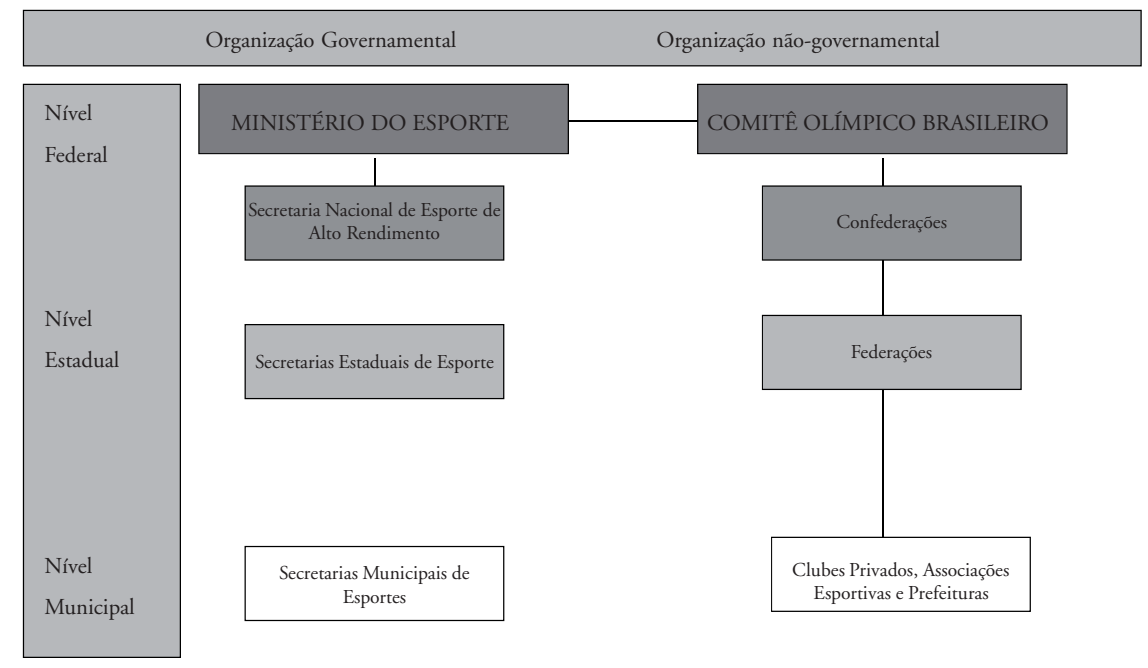

FIGURA 3 - Estrutura organizacional brasileira do esportedealto rendimento (elaborada por MEIRA \&BASTOS, 2011).

Em relação ao FCS 4: “O esporte de rendimento é reconhecido e valorizado como tarefa política: existe um (gabinete) ministro e ministério do esporte", pode-se afirmar que a organização do Ministério do Esporte como existe hoje foi estabelecida em 2003, no primeiro mandato do ex-presidente Lula.

O Ministério do Esporte é responsável por “construir uma Política Nacional de Esporte. Além de desenvolver o esporte de alto rendimento, o Ministério trabalha ações de inclusão social por meio do esporte, garantindo à população brasileira o acesso gratuito à prática esportiva, qualidade de vida e desenvolvimento humano", em termos institucionais, é representado pelo Ministro do Esporte (BRASIL, 2010b).

O Ministério é dividido em quatro secretarias: Secretaria Nacional Executiva, Secretaria Nacional do Esporte Educacional, Secretaria Nacional de Esporte e Lazer, Secretaria Nacional de Esporte de Alto Rendimento e Assessoria Especial de Futebol.

A Secretaria Nacional de Esporte de Alto Rendimento tem por objetivo desenvolver o esporte de alto rendimento nacionalmente, por meio da implementação, supervisão e gerenciamento de programas e projetos governamentais, representada por um Secretário (BRASIL, 2010b). 


\section{Indicador 2: \\ "Existe simplicidade de administração" (FCS 5)}

O FCS 5, referente a este indicador, refere-se ao "Lugar no ranking em pesquisa de eficiência do setor público (European Central Bank, 2003, e outros estudos existentes, se estiverem disponíveis)", documento que não contém informações sobre o Brasil. No estudo original esse FCS também não pode ser analisado, pois de acordo com os autores, os técnicos, atletas e as Confederações pesquisados não foram capazes de fornecer informações sobre este aspecto administrativo (DE Bosscher et al., 2009).

\section{Indicador 3:}

“Os recursos são focados em um número relativamente pequeno de esportes que possuem chances reais de sucesso internacional" (FCS 6)

Em relação ao FCS 6: "Número de Organizações Esportivas Nacionais que são subsidiadas com finalidade para o esporte de elite" - 52 Confederações esportivas são vinculadas ao $\mathrm{COB}$, sendo que todas têm possibilidade de obtenção de patrocínio de origem estatal ou privada, inclusive o próprio COB.

Vinte e nove confederaçóes responsáveis por modalidades olímpicas recebem repasse da verba proveniente da Lei $\mathrm{n}^{\circ} 10.264$ (por volta de $36 \%$ do total), de acordo com critérios pré-estabelecidos.

Os recursos financeiros gerenciados pelo COB são destinados às Confederações por meio de critérios estabelecidos em 2009, com base principalmente nos resultados técnicos durante o último ciclo-olímpico, a saber: a) Nível Técnico; b) Probabilidade e posterior confirmação de classificação entre os finalistas; c) Número de Praticantes da modalidade inscritos ou registrados oficialmente; d) Número de Federações filiadas às Confederaçōes; e) Infraestrutura Técnica e Administrativa para o Desenvolvimento da Modalidade; f) Aquisição de Material e Equipamento para o Desenvolvimento da Modalidade; g) Resultado do Diagnóstico e Análise das Modalidades Olímpicas, realizados pelo $\mathrm{COB}$ anualmente (COB, 2010).

Cada Confederação deve prestar contas sobre a aplicação dos recursos recebidos a cada trimestre. De acordo com o COB (2010), os recursos deverão ser aplicados em: a) Fomento e Desenvolvimento do Desporto (Manutenção da Entidade; Centro de Treinamento; Fomento da modalidade); b) Formação de Recursos Humanos (Clínicas de Treinamento Prático ou Teórico, Cursos Nacionais; Cursos Internacionais; Assembleias, Feiras, Congressos, Simpósios e Seminários Nacionais e Internacionais); c) Preparação Técnica, Manutenção e Locomoção de Atletas (Manutenção e Locomoção de Atletas; Manutenção e Locomoção de Comissão Técnica) d) Participação e Organização de Eventos Esportivos (Nacionais e Internacionais).

O COB disponibiliza, em seu site, os "Boletins Olímpicos", que são documentos nos quais constam as açôes realizadas a cada trimestre por cada Confederação, demonstrando a utilização dos recursos financeiros recebidos de acordo com os critérios estipulados. Além disso, também disponibiliza os documentos chamados "Demonstração da Aplicação dos Recursos Provenientes da Lei Agnelo-Piva", onde é apresentado o balanço financeiro de cada Confederação ao longo do ano, assim como o balanço financeiro do COB (COB, 2010).

\section{Indicador 4: \\ "Comunicação eficaz: existe uma linha ininterrupta entre os diferentes níveis das instituições esportivas" (FCS 7, 8, 9, $10,11,12,13$ e 14)}

Em relação ao FCS 7: "Organizações Esportivas Nacionais recebem informaçôes e serviços de apoio (além do financeiro) sobre diferentes aspectos para desenvolver a capacidade de gerenciamento", foram identificadas iniciativas do $\mathrm{COB}$ em oferecer suporte às Confederações.

Em 2009 e 2010 o COB ofereceu duas edições do "Curso Avançado de Gestão Esportiva", que tiveram por objetivo capacitar profissionais das Confederaçōes Brasileiras Olímpicas em gestão de organizações esportivas olímpicas, estratégica, de recursos humanos, financeira, e de organização de grandes eventos. Os participantes brasileiros que concluírem o curso receberam o certificado de "Gestor Avançado de Esporte do COI” (COB, 2010).

Além disso, o Comitê Olímpico Brasileiro (COB), por meio do Instituto Olímpico Brasileiro, promoveu, no primeiro semestre de 2010, a primeira edição do "Curso Fundamentos da Administração Esportiva" (FAE), voltado para os representantes do $\mathrm{COB}$, do Comitê Paraolímpico Brasileiro (CPB), das Confederações, dos três níveis do governo, de atletas e ex-atletas olímpicos e pan-americanos, de clubes e de instituiçôes esportivas ligadas ao Movimento Olímpico.

Outra ação desenvolvida em 2010 foi a assinatura de termos de cooperação entre o Comitê Olímpico Brasileiro (COB, 2010) e o Exército Brasileiro para 
a realização de cursos e seminários com o objetivo de desenvolver o esporte no Brasil e aumentar o número de profissionais especializados em diversas áreas.

Quanto aos FCS 8 e 9, "Atletas e técnicos recebem informação das organizações de esporte nacionais sobre diferentes aspectos", o COB, por meio do Instituto Olímpico Brasileiro, realizou de 2002 a 2008, 12 Cursos Técnicos de modalidades e Treinamentos em Ciência Esportiva, palestras e seminários e um intercâmbio esportivo para atletas e treinadores. A área de controle de "doping" do COB publica regularmente uma cartilha com dados e orientaçôes a atletas - e a toda Comunidade Olímpica - sobre o uso de medicamentos no esporte. O COB também edita desde 2007 o Boletim técnico-científico Laboratório Olímpico, com temas relacionados a treinamento.

\section{Discussão}

Por meio dos resultados apresentados, é possível verificar que o Brasil possui ações voltadas para o desenvolvimento do esporte de alto rendimento, de acordo com a análise dos indicadores estabelecidos.

No Brasil, em nível nacional, duas organizações são responsáveis pelo desenvolvimento do esporte de alto nível, respectivamente, o Comitê Olímpico Brasileiro (COB) e o Ministério do Esporte, representado pela Secretaria Nacional de Alto Rendimento, como em outros países, como no Reino Unido e Noruega (DE Bosscher et al., 2008). No entanto, em alguns países, o Governo e/ou os Institutos do Esporte são responsáveis pelo desenvolvimento do esporte como um todo.

No Brasil pode ocorrer sobreposição de tarefas e conflito de interesses entre as duas organizaçóes responsáveis pelo esporte de alto rendimento, pois as mesmas possuem programas e projetos isolados que são realizados paralelamente, sem interação entre os mesmos.

Além disso, como apresentado na FIGURA 3: "Estrutura Organizacional Brasileira do Esporte de Alto Rendimento", existe comunicação entre Ministério do Esporte e $\mathrm{COB}$ apenas pelo repasse proveniente da Lei Agnelo-Piva. A comunicação existente entre o Ministério do Esporte e as Secretarias Estaduais e Municipais de Esporte não acontece em relação à implementação de programas e projetos, já que as Entidades Estaduais e Municipais de Práticas Esportivas possuem autonomia para elaborar e administrar seus próprios programas e projetos.
O Conselho Nacional do Esporte, inserido no Sistema Brasileiro do Desporto, conta com a representação individual ou representativa de atletas desde 1993. Em relação às Confederações, são raras aquelas que prevêem a participação de atletas com poder de voto nas decisões sobre as atividades das entidades (HARADA, 2005). Quanto à representação de atletas no COB, em 2009 foi instituída a primeira Comissão de Atletas Olímpicos.

Quanto aos demais FCS do indicador 4, respectivamente: FCS 11 e 12: "Satisfação de atletas e técnicos em relação às informações recebidas das Organizaçōes esportivas nacionais" e FCS 13 e 14: "Satisfação de atletas e técnicos em relação ao envolvimento em políticas das Organizações esportivas nacionais", não foram obtidas informações referentes aos mesmos.

De acordo com a Lei no 9.615 (BRASIL, 1998), "os Estados e o Distrito Federal constituem seus próprios sistemas, respeitadas as normas estabelecidas nesta Lei e a observância do processo eleitoral; aos Municípios é facultado constituir sistemas próprios de desporto, observado o disposto nesta Lei e, no que couber, na legislação do respectivo Estado".

Verificou-se que existe comunicação entre $\mathrm{COB}$ e as Confederações, dado que as Confederaçõos recebem do $\mathrm{COB}$ o repasse dos recursos provenientes da Lei Agnelo-Piva. Para que isso ocorra existem critérios pré-estabelecidos, assim como a necessidade de apresentar planos e relatórios sobre a aplicação dos recursos financeiros recebidos.

Após o entendimento sobre a estrutura organizacional esportiva voltada para o esporte de alto nível, a análise dos fatores recai sobre o suporte financeiro que os chamados "Corpos Nacionais de Esporte CNE" recebem. No Brasil, como vimos, as Confederaçôes recebem recursos do $\mathrm{COB}$, captados por meio da arrecadação de loterias. Algumas Confederações recebem, ainda, recursos de empresas estatais, além de empresas da iniciativa privada. Dessa forma caracteriza-se a não participação direta de investimentos do Governo no esporte de alto rendimento, e sim de Órgãos Governamentais (empresas estatais) e Organizações Esportivas Não-Governamentais (COB). Fato contrário ao verificado com relação aos recursos dos países analisados na pesquisa realizada por De Bosscher et al. (2008), nos quais a principal 
fonte de recursos financeiros era proveniente do Governo. Outro aspecto da análise DE Bosscher et al. (2008) e GREEN e OAKLEY (2001) refere-se à estratégia desenvolvida por países do antigo Bloco Comunista no sentido da aplicação de recursos financeiros em um número pequeno de modalidades esportivas, possibilitando ao país que sua estrutura esportiva seja mais eficiente, aumentando assim, as chances de alcançar sucesso esportivo internacional.

No país, como verificado, 29 confederaçôes de modalidades olímpicas recebem recursos oriundos do COB que são distribuídos pelo mesmo, de acordo com critérios técnicos, de número de participantes nas modalidades e infraestrutura e capacidade gerencial, entre outros. $\mathrm{Na}$ Holanda são $63 \mathrm{CNEs}$ que recebem recursos financeiros do Governo, considerado um número alto de modalidades, além disso, entre essas estão algumas que não representam esportes olímpicos. Já a comunidade de Flandres (Bélgica) repassa recursos financeiros a 26 CNEs, a comunidade de Wallonia para 36, a Noruega para 30 e o Reino Unido para 40 CNEs (De Bosscher et al., 2008).

Portanto, de acordo com exposto, o Brasil poderia criar estratégias para focar a aplicação de recursos em modalidades com chances reais de medalhas e que possuam tradição em Jogos Mundiais e Olímpicos, a fim de potencializar resultados expressivos internacionais.

De Bosscher et al. (2008) também examinaram quais outros tipos de suporte são oferecidos pelas Confederações, além do suporte financeiro. Neste sentido, Reino Unido e Holanda possuem profissionais que auxiliam Confederações e Federações em relação a gerenciamento de projetos, contabilidade, aplicação de recursos financeiros e planos de desenvolvimento de talentos a longo prazo.
$\mathrm{Na}$ realidade brasileira, as ações se dão pela busca da capacitação dos profissionais das áreas técnica, financeira, administrativa, eventos, marketing e relações internacionais que atuam nas Confederaçôes Brasileiras Olímpicas (COB, 2010). A publicação Managing Olympic Sport Organizations (MOSO), produzida pela Solidariedade Olímpica em cooperação com o MEMOS (Master Executif en Management des Organisations Sportives), norteia a programação do curso.

Além do suporte de gerenciamento para as Confederaçôes e Federaçôes, De Bosscher et al. (2008) também analisaram o suporte das Confederações oferecido a técnicos e atletas. Os autores verificaram que na Holanda, Reino Unido, Noruega e Canadá, as Confederações oferecem a técnicos e atletas informaçōes sobre nutrição, critérios de seleção, "doping", treinamento, planos de competição, planos de viagens e pesquisas científicas e que técnicos e atletas se sentem satisfeitos com o nível e a qualidade desse suporte. Este aspecto ainda se encontra incipiente no Brasil, seja por iniciativa do Ministério do Esporte ou do COB.

Além disso, nesses países, os atletas possuem comissões representativas dentro das Confederações. No Canadá, por exemplo, de 11 Confederações, 10 possuem comissões de atletas, sendo que essas representam $76 \%$ dos atletas canadenses. Em outros países essa porcentagem é menor: 35\% na Holanda, 21\% na Noruega e apenas 10\% dos atletas são representados por comissões em Flandres (DE Bosscher et al., 2008). Como vimos, é recentíssima a criação da Comissão de Atletas Olímpicos no Brasil. Portanto, ainda não há condições de se avaliar a repercussão das ações dessa iniciativa, mas existe a expectativa de que este quadro poderá ser modificado tendo em vista que um de seus objetivos é estimular a criação de Comissões de Atletas nas Confederações Brasileiras de esportes olímpicos.

\section{Conclusão}

De acordo com o objetivo proposto, de descrever a organização, as estruturas e as políticas para o esporte de rendimento no Brasil, por meio da análise da estrutura organizacional e das ações realizadas para o desenvolvimento de esporte de alto nível brasileiro, com base nos fatores críticos dos indicadores do Pilar 2, "Organização e Estrutura de Políticas para o Esporte" do modelo SPLISS, verificou-se que:

Em relação ao Indicador 1: "Existe uma forte coordenação entre todas as instituiçôes de esporte de elite, com clara definição e sem sobreposição das diferentes tarefas", o país possui ações voltadas para o desenvolvimento do esporte de alto nível oriundas do $\mathrm{COB}$ e do Ministério do Esporte, as quais são isoladas, algumas delas semelhantes, mas sem que haja uma diretriz central norteadora para as mesmas.

Em relação ao Indicador 3: "Os recursos são focados em um número relativamente pequeno de esportes que possuem chances reais de sucesso internacional", 29 Confederaçôes recebem o repasse 
da verba proveniente da Lei Agnelo-Piva, desde que atendam determinados critérios pré-estabelecidos. No entanto, não existem estratégias para focar a aplicação de recursos em modalidades com chances reais de medalhas e que possuam tradição em Jogos Mundiais e Olímpicos, a fim de potencializar resultados expressivos internacionais.

Em relação ao Indicador 4: "Comunicação eficaz: existe uma linha ininterrupta entre os diferentes níveis das instituiçōes esportivas", existem ações do COB em relação ao oferecimento de cursos para as Confederaçōes e técnicos. E a participação de atletas nas instituições nacionais de esporte ainda é bastante restrita e recente.

Com relação aos resultados de outras pesquisas comparativas internacionais sobre o tema estudado, o esporte brasileiro necessita de estruturação esportiva nacionalmente, para que programas e projetos esportivos funcionem de maneira regional, mas de modo integrado com diretrizes propostas e coordenadas por órgãos governamentais e entidades nacionais do esporte.
A limitação do presente estudo está no fato de que a maioria das informaçóes foi retirada de sites, pois grande parte das fontes necessárias para este tipo de pesquisa não estão disponíveis para consulta no meio acadêmico. As entidades de administração do esporte no Brasil não elaboram material institucional consistente, não existe divulgação ampla das atividades desenvolvidas, assim como as ações administrativas e políticas para a área esportiva não tem sido objeto de pesquisa científica pela academia.

Sugere-se a realização de mais estudos desta natureza, com maior profundidade e através de outros instrumentos de pesquisa, como por exemplo, entrevistas e aplicação de questionários objetivos, específicos para cada modalidade ou grupo de modalidades esportivas. Trabalhos científicos desta natureza poderão contribuir para traçar cenários mais realistas, com o objetivo de fundamentar ações mais efetivas para o desenvolvimento do esporte de rendimento no país.

\title{
Nota
}

1. Neste estudo são apresentados dados preliminares do projeto de pesquisa em andamento que está sendo realizado pelo LATECA (Laboratório de Treinamento e Esporte para Crianças e Adolescentes) e o GEPAE (Grupo de Estudos e Pesquisa em Administração Esportiva) em parceria com o consórcio internacional SPLISS (Sports Policies Leading to International Sport Success).

\begin{abstract}
Analysis of the organizational structure of elite sport in Brazil: a preliminary study

In several countries, the organization and structure of sport policies are made through programs developing in the whole country. This research analyzed the organization, structures and policies for elite sport in Brazil. The analysis has been based on the 14 Critical Success Factors (CSF) which refer to the four indicators of Pillar 2 from SPLISS model - (Sports Policies Leading to Sport Success), as proposed by De Bosscher et al. (2009). It has been verified that the country performs isolated actions focused on the development of elite sport that comes from COB and the Ministry of Sports; there is no prioritization of the application of the financial expenditure in sports which have a real chance of medals; there are $\mathrm{COB}$ actions related to the offering of courses to Confederations and coaches; and the participation of athletes in national sports institutions are recent and restrict.
\end{abstract}

UNITERMS: Sport organization; Sport policies; Elite sport. 


\section{Resumen}

Análisis de la estructura organizativa del deporte de alto rendimiento en Brasil: un estudio preliminar

En diversos paises, la estructura organizacional de las modalidades deportivas se define por programas del deporte a nivel nacional. Este estudio ha tenido por objetivo analizar la organización, estructuras y políticas para el deporte de alto rendimiento en Brasil. El análisis se ha fundamentado en los 14 Factores Críticos para el Éxito (FCS) relativos a los 4 indicadores que componen el Pilar 2 del modelo SPLISS (Sports Policies Leading to Sport Sucess) (De Bosscher et al., 2009). Se ha verificado que Brasil tiene acciones aisladas provenientes del Ministerio del Deporte y del Comité Olímpico Brasileño (COB); no existe priorización en la aplicación de los recursos financieros en las modalidades con oportunidades reales de medallas; hay acciones del COB relativas al ofrecimiento de cursos para las Confederaciones y técnicos; la participación de atletas en las instituciones nacionales de deporte todavía es muy limitada e incipiente.

Palabras clave: Organización deportiva; Políticas deportivas; Deporte de rendimiento.

\section{Referências}

BRASIL. Lei no 9.615, de 24 de março de 1998. Institui normas gerais sobre o desporto e dá outras providências. Disponível em: <http://www.planalto.gov.br/ccivil_03/Leis/L9615consol.htm>. Acesso em: 14 abr. 2010.

Lei no 10.264, de 16 de julho de 2001. Acrescenta inciso e parágrafos ao art. 56 da Lei no 9.615, de 24 de março de 1998, que institui normas gerais sobre desporto. Disponível em: <http://www.planalto.gov.br/ccivil_03/Leis/ LEIS_2001/L10264.htm>. Acesso em: 14 abr. 2010.

Lei no 11.438, de 29 de dezembro de 2006 (Lei de Incentivo Fiscal ao Desporto). Disponível em: <http:// www.planalto.gov.br/CCIVIL/_Ato2004-2006/2006/Lei/L11438.htm>. Acesso em: 13 abr. 2010.

BRASIL. Transparência Pública. Transferência de Recursos por Programa 2009. Disponível em: <http://www.portaltransparencia.gov.br/PortalTransparenciaTRProgramaPesquisaAcao.asp? Exercicio $=2009 \&$ textoPesquisaPrograma $=\& c 0$ digoPrograma=0181\&nomePrograma=Brasil\%20no\%20Esporte\%20de\%20Alto\%20Rendimento\%20-\%20Brasil\%20 Campe\%E3o>. Acesso em: 15 abr. 2010a.

BRASIL. Ministério do Esporte. O Ministério. Disponível em <http://portal.esporte.gov.br/>.Acesso em: 20 jan. $2010 \mathrm{~b}$. COMITÊ OLÍMPICO BRASILEIRO (COB). Demonstração da aplicação dos recursos provenientes da Lei AgneloPiva 2009. Disponível em <http://www.cob.org.br>. Acesso em: 15 maio 2010.

CONFEDERAÇÃO BRASILEIRA DE ATLETISMO. A CBAT (Federaçóes). Disponível em <http://cbat.org.br>. Acesso em: 15 maio 2010.

CONFEDERAÇÃO BRASILEIRA DE DESPORTOS AQUÁTICOS. CBDA (Federações). Disponível em <http:// www.cbda.org.br/>. Acesso em: 15 maio 2010.

CONFEDERAÇÃO BRASILEIRA DE BADMINTON. Filiados. Disponível em < http://www.badminton.org.br/ badminton.asp>. Acesso em: 15 de maio de 2010.

CONFEDERAÇÃO BRASILEIRA DE TIRO COM ARCO. Federações. Disponível em < http://www.cbtarco.org. br/>. Acesso em: 15 maio 2010.

CONFEDERAÇÃO BRASILEIRA DE TRIATLHON. Federações. Disponível em < http://www.cbtri.org.br/home. asp>. Acesso em: 15 maio 2010.

DE BOSSCHER, V.; BINGHAM, J.; SHIBLI, S.; VAN BOTTENBURG, M.; DE KNOP, P. The global sporting arms race: an international comparative study on sports policy factors leading to international sporting success. Oxford: Meyer \& Meyer Sport, 2008. DE BOSSCHER, V.; DE KNOP, P.; VAN BOTTENBRUG, S.; BINGHAM, J. Explaining international sporting success: an international comparison of elite sport systems and policies in six countries. Sport Management Review, Sydney, v.12, p.113-36, 2009.

DE BOSSCHER, V.; SHIBLI, S.; VAN BOTTENBRUG, M; DE KNOP, P.; TRUYENS, J. Developing a method for comparing the elite sport systems and policies of nations: a mixed research methods approach. Journal of Sport Management, Champaign, v.24, n.5, p.567-600, 2010. 
De ROSE, D.J.; DESCHAMPS, S.; KORSAKAS, P. Situaçōes causadoras de "stress" no basquetebol de alto rendimento: fatores competitivos. Revista Paulista de Educação Física, São Paulo, v.13, n.2, p.217-29, 1999.

DIAS, H.P.; BASTOS, F.C. Analysis of the Brazilian sports incentive program. In: SPORT stad okonomik: sport and urban economics. Schorndorf: Hofmann, 2010. v.12, p.35-42.

DIGEL, H. A comparison of competitive sport systems. New Studies in Athletics, London, v.17, n.1, p.37-50, 2002a. . The context of talent identification and promotion: a comparison of nations. New Studies in Athletics, London, v.17, n.3/4, p.13-26, 2002b.

FEDERAÇÃO PAULISTA DE VOLLEYBALL. Clubes filiados. Disponível em <http://www.fpv.com.br/ > . Acesso em: 15 de maio de 2010.

GREEN, M. Changing policy priorities for sport in England: the emergence of elite sport development as a key policy concern. Leisure Studies, Colchester, v.23, n.4, p.365-85, 2004.

GREEN, M.; OAKLEY, B. Elite sport development systems and playing to win: uniformity and diversity in international approaches. Leisure Studies, Colchester, v.20, p.247-67, 2001.

HARADA, G.S. Constituição organizacional de entidades nacionais de dministração do desporto: análise dos sistemas eleitorais e da representatividade dos atletas. 2005. Monografia (Bacharelado em Esporte) - Escola de Educação Física e Esporte, Universidade de São Paulo, São Paulo, 2005.

HOULIHAN, B.; GREEN, M. Comparative elite sport development: systems, structures and public policy. Burlington: Elsevier, 2008.

INTERNATIONAL OLYMPIC COMMITTEE (COI). Olympic Games (Winter Games). Disponível em: <http// www.olympic.org>. Acesso em: 20 jan. 2010.

MATSUDO, V.K.R. Detecção de talentos. In: GHORAYEB, N.; BARROS, T. O exercício: preparação fisiológica, avaliação médica, aspectos especiais e preventivos. São Paulo: Atheneu, 1999.

MEIRA, T.B.; BASTOS, F.C. Estrutura organizacional esportiva. In: BÖHME, M.T.S. (Org.). Esporte infanto-juvenil: treinamento a longo prazo - talento esportivo. São Paulo: Phorte, 2011.

THUMM, H. Talent identification in Indonesia: a model for other countries? New Studies in Athletics, London, v.21, n.2, p.29-39, 2006.

VAN ROSSUM, J.H.A. Perceptions factors of determining in athletic achievement: an addendum to Hyllegard, et al. (2003). Perceptual and Motor Skills, Missoula, v.98, p.81-5, 2004.

VERGARA, S.C. Projetos e relatórios de pesquisa em administração. 7. ed. São Paulo: Atlas, 2006.

ZIEMAINZ, H.; GULBIN, J. Talent selection: identification and development exemplified in the Australian talent search programme. New Studies in Athletics, London, v.17, n.3/4, p.27-32, 2002.

ENDEREÇO

Tatiana de Barros Meira

Estrada do Embu, 1563 - casa B27S

06713-100 - Cotia - SP - BRASIL

e-mail: tati_meira7@hotmail.com
Recebido para publicação: 29/11/2010

1a. Revisão: 23/11/2011

2a. Revisão: 08/03/2012

3a. Revisão: 16/ 04/ 2012

Aceito: 02/ 05/2012 